\title{
Maintaining sustainability of acute care hospitals
}

\author{
Michael M. Costello*1, Daniel J. West ${ }^{1}$, Bernardo Ramirez ${ }^{2}$ \\ ${ }^{1}$ Department of Health Administration \& Human Resources, The University of Scranton, Pennsylvania, United States \\ ${ }^{2}$ Department of Health Management \& Informatics, University of Central Florida, Orlando, Florida, United States
}

Received: September 2, 2014

Accepted: November 7, $2014 \quad$ Online Published: November 17, 2014

DOI: $10.5430 /$ jha.v4n1p9

URL: http://dx.doi.org/10.5430/jha.v4n1p9

\begin{abstract}
Given the significance of hospital costs as a component of a nation's total health care spending, governments are giving increased scrutiny to hospital privatization as a means of controlling cost escalation. While the means of privatization may differ among nations, such transitions mean the introduction of market forces into the supply and availability of hospital services. Correspondingly, nations must determine whether market forces alone should determine whether specific hospitals should be allowed to close based upon the owner's sole determination. Responses to the financial crisis of 2007-2009 show that government intervention preserved several financial institutions whose closure or bankruptcy would have meant the termination of critical financial services. The authors believe that such intervention can be rationalized in certain cases of potential acute care hospital closures. Several international examples of health policies intended to maintain government involvement after hospital privatization are included.
\end{abstract}

Key Words: Hospital privatization, Hospital closures, Government intervention in hospitals

\section{Hospital consolidation}

Acute care hospitals occupy a pre-eminent position in the health care systems of most nations. As the locus of much of the care provided to the citizens of a given country, these hospitals also represent a significant portion of most nation's total health expenditures.

The concern over rapidly increasing hospital costs has led many nations that previously favored government ownership of hospitals to consider privatization with the goal of reducing government expenditures associated with hospital ownership. The privatization initiatives often result in the acquisition of hospitals by for profit owners as well as the transfer to non-profit, non-governmental owners.

However, expenditures for acute care hospital services appear to be a universal concern for hospital owners. In the US alone, spending on hospital services accounts for approxi- mately $31 \%$ of total health spending ${ }^{[1]}$ and public insurance program such as Medicare and Medicaid are expected to reduce hospital payment rates in the near future (ibid).

Even though hospital ownership continues in private entities, government public insurance programs remain responsible for paying for hospital services, subject to fiscal budgetary constraints, and private insurers emphasize efforts to restrict hospital payments with an eye toward moderating health insurance premium increases.

While revenues are being constrained, costs often increase at the same time, impacting positive operating margins on hospital profits. When private physicians sense deteriorating hospital financial performance they often begin to shift their admissions and hospital work to other competing facilities, thereby further exacerbating revenue deterioration. With the subsequent focus on operating profitability, hospi-

\footnotetext{
*Correspondence: Michael M. Costello; Email: michael.costello@scranton.edu; Address: Department of Health Administration \& Human Re-
} sources, The University of Scranton, Pennsylvania, United States. 
tals often find themselves short of funds to cover bonds and other debt obligations, including employee pension plans.

Financial pressures have forced the hospital industry into facility closures, mergers, consolidations and acquisitions, but less attention has been given to the impact on consumers and access to health care services. ${ }^{[2]}$

Increasing financial pressures in acute care hospitals have resulted in lower operating margins that could compromise quality of care. In the US several studies have examined payment policy changes in Medicare and Medicaid and the adverse impact on intensity of care and reduced services. As payments decline and hospital operations are compromised there is a strong evidence to suggest that quality of care may deteriorate. Financial distress also impacts investments in physical plant, technology acquisition, and the retention of labor force.

In many nations, hospital ownership is being consolidated in large for profit companies and non-profit systems. Such consolidations allow owner organizations to reduce costs by spreading administrative overhead over a larger number of hospitals. But with increasing cost pressures facing hospital operators, it would seem inevitable that for profit and nonprofit hospital systems would contemplate closing some facilities with marginal financial performance. Such closures might be expected to result in reduced access for certain hospital patient populations. The prospect of such hospital closures invariably leads to the question: how might governments intervene to keep certain hospitals open so as to assure access in certain geographic locales.

The question itself raises the issue of the conflicting interests of private hospital owners seeking to maintain the financial viability of their systems and governmental authorities attempting to meet their obligation of assuring reasonable access to acute care hospital services for their citizens.

\section{Government response to the 2007 finan- cial crisis}

The response of world governments to the financial crisis known as the Great Recession demonstrates the extent to which regulatory authority can be exercised in private markets, and provides some insight as to how governments might address markets for hospital services.

The Great Recession which began in the fourth quarter of 2007 sent shockwaves far beyond the shores of the United States and Western Europe, causing turmoil in equity markets around the world. The unraveling of the market for mortgage backed securities caused a deep sense of panic among world financial leaders. Commentators speculated on a meltdown of international financial markets.

By September of 2008, officials at the U. S. Treasury Department and the Federal Reserve began to fear that market panic might cause the collapse of major financial institutions. ${ }^{[3]}$ At hastily summoned meetings in New York and Washington, D.C., government officials and senior staff of major U. S. based financial institutions began to consider steps that would have been previously unheard of in addressing financial market turmoil.

US federal officials began to strongly encourage actions to preserve major financial institutions. J. P. Morgan, one of the world's largest investment banks, was actively encouraged by the U. S. government to acquire Bear Stearns, a failing investment bank. Government officials also encouraged J. P. Morgan to acquire Morgan Stanley, another preeminent financial institution. When that course of action proved to be unworkable, the government then encouraged Morgan Stanley to merge with Mitsubishi, a huge Japanese bank.

In order to prevent the failure of international insurance giant AIG, the government acquired more than $79 \%$ of the capital stock of the firm, leading to lawsuits from existing shareholders who saw their investment interests diluted. The US government rationalized this step by arguing that AIG was a counter party in several derivative contracts tied to the mortgage backed securities market, and that if AIG was unable to make good on those contracts, world financial markets would deteriorate further.

These unprecedented steps represented drastic departures from previous government policies, and led to staunch criticism from certain political quarters since taxpayer money was being used to "bail out" or preserve private companies that had become imperiled through mismanagement. But government regulators feared that lack of intervention would lead to economic and financial turmoil that could result in lower tax revenues and higher borrowing costs, thereby endangering national fiscal health.

Such a drastic turn in government policy leads to an intriguing question: might governmental regulators take a similar approach in consolidating or investing in certain acute care community hospitals so as to preserve access to hospital services in some local and regional markets? And despite how radical such policy might seem in light of past practices, might popular support develop for the implementation of such policy? Given the financial pressures facing acute care hospitals in several nations, the prospects for such action are not beyond the realm of possibility. In the global financial crisis, government intervention was premised on the need to stabilize world financial markets. Intervention in hospital markets would be premised on government need to preserve access to healthcare for a nation's citizens, arguably a major responsibility of any national government.

Private market ownership of hospitals assumes, to a certain degree, that market forces will govern the provision of hospital services. Subject to government oversight, private owners may purchase existing hospitals, build new facilities, 
or possibly close hospital facilities that do not meet the owners' parameters for financial performance and/or patient utilization. However, such market-based determinations may reasonably be expected to conflict with government obligations to provide for public welfare by providing reasonable access to hospital services. The allowance for the provision of private ownership arguably does not relieve government of its responsibility to assure reasonable access to hospital care. In a market-based economy, a well recognized obligation of government is to address market failure, an example of which might be the threatened closure of certain acute care hospitals.

Adam Smith, recognized as the founder of modern economics, had argued against government intervention in competitive markets. ${ }^{[4]}$ Economists who followed Smith's line of thinking believed that free markets, functioning independent of government intervention, would produce optimal results for national populations. When the Great Depression unfolded in the early 1930's, prominent economists like Great Britain's John Maynard Keynes argued that government had a need to intervene in order to keep markets from failing, thereby causing disastrous economic consequences. The key consideration now appears to be the balance between governmental intervention and market forces.

The important question is not whether government or markets are "better", but how to balance and blend regulation in competition to optimize social welfare and meet necessary constraints. To do this, a consensus about what constitutes a just society is needed. ${ }^{[5]}$

\section{The impact of hospital closures}

When attempting to evaluate the effects of hospital closures, published research has distinguished between urban and rural hospital closures.

In a working paper published by the U.S. National Bureau of Economic Research ${ }^{[6]}$, the study authors concluded that while urban hospital closures in Los Angeles County, California may have generated "extremely important" efficiency savings, the closures had negative impacts on certain patient populations.

Case-specific mortality data suggests that urban hospital closures also have implications for the population more generally. There is strong evidence that increased distance to the nearest hospital is associated with higher mortality counts from emergent conditions, such as heart attacks and unintentional injuries. There is some evidence that distance to the nearest hospital is positively related to infant mortality, though these results are less robust.

Rosenbach and Dayhoff ${ }^{[7]}$ argued that "rural hospitals were not more likely to close than urban hospitals, controlling for other factors". However, they concluded that rural hospitals were at greater risk of closure because of smaller size, low occupancy, higher expenses than revenues, and proportionately greater bad debt.

A U.S. study by the North Carolina Rural Health Research Program $^{[8]}$ studied areas where rural hospital closures had occurred and found: “... evidence suggestive of some negative effects of hospital closures on these communities. These negative effects include difficulty in recruiting and retaining physicians, concern of residents over the loss of their local emergency room, and increased travel times to receive hospital services. Increased travel times are indicated to impact most significantly on vulnerable populations, such as the elderly, the disabled, and persons of low socioeconomic status."

In terms of the impact of rural hospital closures on a community's economic health, Holmes, Slifkin et al. ${ }^{[9]}$ wrote that "the closure of the sole hospital in the community reduces per-capita income by $\$ 703 \ldots$ and increases the unemployment rate by 1 to 6 percentage points".

Bindman, Keane and Luvie ${ }^{[10]}$ studied the impact of the closing of a California public hospital on patient's access to health care and health status. Their work showed "a significant effect on access to health care and was associated with a decline in health status".

When examining the effects of hospital bed reduction in Europe, $\mathrm{McKe}{ }^{[11]}$ wrote that in Europe, "there is remarkably little published research on the reconfiguration of hospital systems". He attributed this to the unwillingness of funding agencies to support organizational research in the health sector and the absence of developed systems for collecting data on a population basis. He writes that with the exception of Scandanavia, "few countries in Europe have such systems". He also claims that research done on the US health care system does not have much applicability in Europe because of the US reliance on a market-based system.

\section{The role of government}

In his New York Times best-seller survey of world health care systems, T.S. Reid ${ }^{[12]}$ wrote of the "central moral question" posed by a nation's health care system: guaranteeing access to care when it is needed: "... both the Asian nation [Taiwan] steeped in Confuscian teachings and the European nation [Switzerland] built on Judeo-Christian principles came to the same conclusion on the central moral question... Both countries decided that society has an ethical obligation - as a matter of justice, of fairness, of solidarity - to assure everybody has access to medical care when it's needed (p. 183)."

While acute hospital care is only one component of medical care, it would seem to be an extremely important component. If any nation espoused a public policy of guaranteeing access of every citizen to necessary medical care, acute care hospitals would be an extremely important link 
in that care continuum. When government maintains ownership of acute care hospitals, the decision to keep certain hospitals open is fundamentally a political decision manifested in government regulatory policy. If hospitals are privately owned as for-profit- or non-profit facilities, government maintains legal authority under several theories to ensure that facilities remain open to ensure access.

In the following sections we review how these ideas affect and are impacting hospitals and healthcare systems in some specific national and regional cases.

\subsection{Slovak Republic}

The Slovak Republic is located in Central Europe, is a member of the United Nations, a member of OECD since 2000, a member of NATO and the EU since 2004. The current health care system provides universal coverage, compulsory health insurance and a competitive insurance model with flexible pricing. Since 2005, all insurance companies have moved from public to private ownership. The State owns the largest health care facilities, but as with insurance companies, in 2006 five state-owned facilities were change to "state-owned stock companies". The Ministry of Health plays a central role in monitoring hospital access, cost and quality of care.

According to Szalay, Pazitny, Szalayova, Fresoia, Morvay, Petrone and van Ginneken, ${ }^{[13]}$ the political structure of Slovakia has impacted health care reforms. The Slovak Republic has a parliamentary democracy with many active political parties. Political reforms during 2000-2005 shifted control from the central government to regional and local government levels. The European integration process influenced the institutional shift to the local level. This shift can be seen in health care with self-governing regions impacting outpatient care and issuing permits to health care providers. Self-governing regions also cooperate in monitoring the management of health care facilities and opinions on ethical issues. This transfer of responsibility from the State to the eight self-governing regions was a major move to decentralize power. Self-governing regions own some health care facilities and influence the management of these facilities. The self-governing regions have other competencies including:

- imposing financial penalities on providers;

- temporary revocation of a license;

- issuing permits for operating health facilities;

- appointing ethical committees;

- approving outpatient biomedical research;

- improving the network of providers;

- monitoring health care provisions.

With the decentralization of health care services in 2003 in Slovakia, the ownership of the majority of state health care facilities and services was also moved to the self- governing regions. Further decentralization of primary care was moved to municipalities. It is in the polyclinics that the majority of primary care is delivered throughout Slovakia. The objective of the Slovak health care system is to improve the health status of the population. Since 2006, this view has changed under the new "Government Manifesto" where the State is once again responsible for the health status of the population. This "conventional paradigm" persists today [ibid].

Government intervention has been necessary in the Slovak Republic to advocate and advance needed health policy changes. This is especially true in maintaining universal coverage and addressing social equity issues. The current government wants the burden of health care funding to be sustainable and without creating future debt. With a global focus on quality of care and safety, Slovakia cannot rely on the private sector to address concerns in these key areas. The government has been advocating the use of standard diagnostic and treatment protocols along with increased evidence based medicine (EBM). There is a stronger need for increased public health, patient advocacy and addressing the primary care needs of marginalized populations (e.g., Roma communities). There are other issues facing hospitals with respect to effectiveness and transparency that a market based approach may not adequately address in maintaining stability.

For example, there are issues with unfair competitive practices, lack of influence by consumers, and problems with access to care in rural areas. Government intervention may be necessary to mitigate the impact on healthcare providers. Furthermore, decentralization to self-governing regions and municipalities may create financial pressures and require further reforms to restructure hospital care. Finally, the overall lack of a coherent strategic planning process may create imbalances in primary care, acute care and increase the influence by physicians and insurance companies. Governmental intervention may be necessary to achieve fiscal stability, access equality and achievement of quality outcomes.

\subsection{Republic of Georgia}

Recent developments in the former Soviet Republic of Georgia illustrate how a national government's health policy can be directed to keeping acute care hospitals in operation through legislative enactments.

When the former Soviet Union collapsed in 1991, Georgia and other former members of the Soviet Union found themselves in difficult economic straits. ${ }^{[14]}$ Centralized tax revenues were no longer available to support the health sector of Georgia, which had been modeled on the system of government ownership of hospitals and employment of professionals developed in the former Soviet Union. Following the "rose revolution" of 2003, Georgia moved toward health 
sector privatization. In February of 2007, the Georgian government promulgated The Hospital Master Plan "calling for the near complete privatization of the hospital sector". [15]

Under the provisions of the plan, private investors were allowed to buy old hospitals on prime real estate in certain areas of the country. The investors were required to renovate the facilities and keep them in operation as hospitals for seven years. The plan was amended in 2010 to require private insurance companies participating in state insurance financing schemes to become involved in the hospital privatization effort.

\subsection{Latin America}

Latin American healthcare systems have numerous models throughout the region and are characterized by a mix of public and private organizations. Several countries have insurance programs represented by public payors, social security, and profit- and non-profit organizations. It is this diversity in pension programs and health care reform that has challenged financial sustainability and impacted outcomes.

The public sector is typically represented by federal, state or local services run by Ministries of Heath $(\mathrm{MOH})$ that in some cases not only regulate the health sector, but also provide services from primary healthcare to tertiary healthcare using highly specialized hospitals. This configuration of hospitals and ambulatory services is organized to care for the uninsured and/or low-income populations and also other specialized subsets of the population. For example, some of these services have been expanded with the aim of achieving universal coverage by incorporating public insurance mechanisms as in Mexico's "Popular Insurance"[16] and multilevel systems with an emphasis on primary health ambulatory care in Peru's "Solidarity System SISOL". [17] In some instances, these public health services and hospitals are highly technological and well-recognized, as in the case of the National Institutes of Health in Mexico that consist of 12 special decentralized institutions with advanced medical and research facilities that are considered the leading specialty centers in the country. ${ }^{[18]}$

Throughout Central and South America, another arrangement of healthcare organizations is comprised of social security institutions, which are owned and administered by boards with representatives from government and private employers, providing employment benefits coverage to their affiliates and their families that in most cases include comprehensive health services. In many cases, specially designated social security organizations cover specific groups (e.g. the armed forces) or special sectors (e.g. petroleum or electrical power unions). The delivery of services under this type of model places additional financial pressures on countries trying to maintain a pluralistic system of access and market segmentation. Variation in patient outcomes causes concern about quality of care.

Published by Sciedu Press
A third group is the for-profit and non-profit sector. In Latin America, for-profit hospitals are the most common, traditionally taking the form of small, physician-owned hospitals. Large hospital chains are mostly found in urban areas, and there are relatively few multi-hospital systems as are typically found in the United States. For-profit hospitals are vulnerable to closure, not primarily from lack of sufficient profits, but more often from an inability to cover rising operating costs. The non-profit sector is characterized by charitable organizations that serve marginalized populations or immigrants and receive significant government subsidization.

While economic growth in most Latin American countries has been strong over the last decade, health disparities are prevalent and in many instances differences in care have become more significant. In countries including Peru, Chile, Brazil and Colombia, with the expansion of wealth and trade, poverty and child mortality have been reduced with the relative growth of the middle class. ${ }^{[19]}$ At the same time, governmental health organizations have experienced more demand and an increasing lack of basic medical resources with a reduced capacity to maintain their technological capacity, especially those serving rural and sub-urban populations. In contrast there has been growth and improvement of the hospital private sector with new facilities in large and middle size cities. This changing dynamic has impacted outcome health indicators.

Documented changes in quality of care has prompted the use of new delivery models where private health insurance has flourished and the transfer of public hospitals to private facilities has increased under private-public partnerships (PPP). These private investment partnerships have been developed in other parts of the world as well and are having different results in Latin America countries. Part of the problem is that it is too early to evaluate the results ${ }^{[20]}$ of these models to determine if cost, access and quality are favorably impacted. For example, in Mexico there are now several examples of PPPs where private investors provide the capital for the facility construction, improvement, technology, equipment management, and delivery of the diagnostic services for a period of 25 years. In return, the governmental health organization operates the medical services of the hospital and ambulatory care facilities. The International Finance Corporation that has financed several of these arrangements in Mexico has reported success with two new hospitals in Toluca and Tlalnepantla, where a partnership between the social security institution and a private health insurer have increased the number of patients served to about one million people covered in a formerly underserved area. Through this partnership, the operating costs were reduced by a third, and the hospitals have the first elements of a "green" social infrastructure in Mexico. ${ }^{[21]}$

Employment continues to increase as the economic development of Latin American countries progresses, but the tra- 
ditional model of social security institutions has been challenged by the number of affiliates and the increasing costs of healthcare. In most countries, once highly advanced and modern social security facilities have been struggling to maintain their quality and to upgrade their medical equipment. Several countries (Argentina, Chile and Peru) have moved from self-contained health provider organizations, to financing and subcontracting entities that have promoted the development of the private sector partnerships. In some countries like Colombia, the lack of timely payments from the government and social security ministry have put in jeopardy the stability and viability of the private sector providers, and at the same time, increases in insurance rates and healthcare costs have diminished the capacity of the public to access and use private health services.

\subsection{The United States of America}

In the U.S.A., approximately $74 \%$ of all private acute care community hospitals are non-profit, and the vast majority of these are tax-exempt in recognition of a charitable purpose. $^{[22]}$ These facilities pay no federal or state taxes and enjoy financial support from private sector donors. Courts in the U.S.A. have examined the charitable traditions of some of these institutions and have ordered the hospitals to remain open in recognition of the charitable support they have received.

In November, 2013 a New York State Supreme Court Justice prohibited State University of New York (SUNY) Downstate from closing Long Island College Hospital (LICH) in Brooklyn, an acute care facility which it had owned and operated for the previous two years. ${ }^{[23]}$

The hospital had been suffering operating losses for many years. In 2011, the judge had approved the merger of LICH and SUNY Downstate on the condition that SUNY Downstate keep the hospital in operation. As part of the transaction, LICH had transferred properties to Downstate estimated to be worth $\$ 1$ billion. When Downstate announced plans to close the hospital earlier in 2013, the judge ordered Downstate to return all of the assets to Continuum Health Partners, Inc., the hospital's previous owner. The assets included a \$135 million permanent endowment, established in the late 1990's, from which funds had been borrowed, but never repaid by the hospital.

The judge ordered Downstate to repay the borrowed funds to the permanent endowment and keep the hospital open until a new operator is found. The new buyer would then have the benefit of the replenished endowment and all of the assets that had been transferred to Downstate.

A Catholic hospital in Los Angeles, California sought to enter into a lease with a business corporation for the operation of the hospital and to use the proceeds from the lease payments to open additional outpatient clinics in its service area. ${ }^{[24]}$ A state appellate court reversed the trial court and ruled that Queen of Angels Hospital Corporation could not cease the operation of the hospital. The court cited the hospital's articles of incorporation, as amended 30 years earlier, which cited its main purpose to be the operation of the hospital. The corporation had consistently represented to the public, and to federal, state and local taxing authorities that it was a hospital. The court said that if the corporation wished to cease operation as a hospital, it would have to relinquish control of its assets (the fully equipped hospital) to the "successor distributees".

\section{Conclusion}

When financial and market forces cause a hospital to consider closure, national regional and state governments have policy options available to keep hospitals open. However, prior to implementing these options, hospital regulators at the appropriate level of government should identify the specific hospital facilities within their jurisdiction that merit invoking these policy options. Rather than waiting until a hospital is threatened with closure, regulatory officials should identify those hospitals that are considered crucial to maintaining necessary access for the jurisdiction's population.

Recognizing the financial difficulties of maintaining government-owned public acute care hospitals, the former Soviet Republic of Georgia modified its hospital licensure laws to allow the sale of public hospitals to private investors on very generous terms in return for the investors committing to keeping the facilities open as acute care hospitals for a minimum of seven years. In Slovakia, larger acute hospitals were converted to governmental facilities under regional control as part of an effort to keep the acute care hospitals in operation. US courts have made use of tax exemption and charitable bequest laws to prevent the closure of acute care facilities. Any nation which subjects hospital mergers or sales to anti-trust scrutiny can use consent decrees as a means to compel the new owner to keep certain facilities in operation. Latin American nations have used PPP.

Private ownership of acute care hospitals is widely recognized as a desirable component of many national health care systems. Whether the ownership is in a for-profit or nonprofit organizational model, the benefits of competitive markets for hospital services are well known.

Sometimes private markets have been known to fail and government intervention to address market failure is an accepted remedy in many nations. If private market ownership leads to hospital closures, with discernible impacts on population access and quality of care, government must respond rather than allowing the competitive marketplace to be the sole arbiter of hospital survival. Governments have an obligation to provide for public health as one aspect of commonly recognized political powers. Providing reasonable access to acute care hospital services, including the preservation of certain facilities, is a government responsibility. 
As this paper suggests, government intervention has a role to play in keeping acute care hospitals in operation so as to ensure access to necessary medical care for its citizens. Further research is encouraged in an effort to determine the extent to which government health policy makers have identified acute care hospitals which must be kept open to ensure reasonable access to prospective patients. The criteria by which these determinations are made should be disclosed and examined as part of the research effort. Additional research should also look at hospital licensure regulations and how the law can be used to keep specified acute care hospi- tals in operation during extreme financial distress.

Health care reform worldwide will continue to test the sustainability of acute care hospitals within national health systems. Governmental officials and health system managers must look carefully at sustainability strategies and health management educators must emphasize key competencies necessary to manage system change effectively. Policy makers must carefully consider governmental sustainability initiatives to limit worldwide competitive market forces as the sole determinants of acute hospital access.

\section{References}

[1] Prescription for Change. The Economist. June 29, 2013; 61

[2] Lesser, CS, Ginsburg, PB. Update on the Nation's Health Care System: 1997-1999. Health Affairs. Nov/Dec 2000; 206-216. http: //dx.doi.org/10.1377/hlthaff.19.6.206

[3] Sorkin, AR. Too Big to Fail. New York: Penguin Group (USA) Inc. 2009.

[4] Smith, A. The Wealth of Nations. Bantam Classic Edition 2003. New York: Bantam Books; 1776.

[5] Getzen, T. Health Economics. Second edition. New York: John Wiley and Sons, Inc; 2004.

[6] How far to the hospital? Working paper 10700. National Bureau of Economic Research. August, 2004.

[7] Rosenbach, Dayhoff. Access to care in rural America: Impact of hospital closures. Health Care Financing Review. Fall, 1995; 17(1): 15-37. PMid: 10153469.

[8] Effects of rural hospital closure on access to care. Working paper No. 58. North Carolina Rural Health Research Program. 1998.

[9] Bindman, Keane, Lurie. A public hospital closes. JAMA. Dec. 12, 1990; 264 (22): 2899-2904. PMid: 2232084. http://dx.doi.org /10.1001/jama.1990.03450220065024

[10] Holmes, GM, Slifkin, RT, Randolph, RK, et al. The Effect of Rural Hospital Closures on Community Economic Health. Health Services Research. 2006; 41(2): 467-485. PMid: 16584460. http: //dx.doi.org/10.1111/j.1475-6773.2005.00497.x

[11] McKee, M. Reducing hospital beds. Policy brief No. 6. European Observatory on Health Systems and Policies. 2004.

[12] Reid, T.R. The Healing of America. London: Penguin Books Ltd. 2009; 183. PMid: 19177340.

[13] Szalay, T, Pazitny, P, Szalayova, A, et al. Slovakia: Health System review. Health Systems in Transition. 2011; 13(2): 1-200.

[14] Verulava, T, Kalandadze, T. Health Care System in Georgia. A. Ziodze and O. Gerzmava, eds. Tbilisi, Georgia: State Medical Insurance Company of Georgia. 2001.
[15] Schecter, K. The Privatization of the Georgian Healthcare System. Anthropology of East Europe Review. Spring 2011; 29(1): 16-22.

[16] Frenk, J, Gomez-Dantes, O, Knaul, F. M. WHO I The democratization of health in Mexico: financial innovations for universal coverage. [2009] Retrieved December 10, 2013. Available from: http: //www . who. int/bulletin/volumes/87/7/08-053199/en/

[17] Arroyo, J, Pastor-Goyzueta, A. La innovación en la organización de servicios con el Sistema Metropolitano de la Solidaridad en Perú. Revista Panamericana de Salud Pública. 33(6): 391397. [2013] Retrieved December 10, 2013. Available from: http: //www.scielosp.org/scielo.php?script=sci_art text\&pid=S1020-49892013000600002\&lng=en\&tlng=es

[18] Secretary of Health Mexico. National Institutes of Health Commission. [2013] Retrieved December 3, 2013. Available from: http: //www. ccinshae.salud.gob.mx/2012/ins.html

[19] UNDP. Human Development Report 2013: The Rise of the South: Human Progress in a Diverse World. Retrieved December 15, 2013. Available from: http://www.undp.org/content/dam/phili ppines/docs/HDR/HDR2013\%20Report\%20English.pdf .

[20] The Global Health Group. Public Private Investment Partnerships for Health: An Atlas of Innovation. Global Health Sciences at the University of California in San Francisco. USA. [2010] Retrieved December 3, 2013. Available from: http://globalhealthsciences.ucsf .edu/sites/defaul t/files/content/ghg/hsi-ppip-atlas.pdf

[21] International Finance Corporation. Mexico: Toluca and Tlalnepantla Hospitals. Success Stories: Public Private Partnerships. [2011] Retrieved December 3, 2013. Available from: http://www.ifc . org/wps/wcm/connect/1b1acf00498390978294d2336b93d7 $5 \mathrm{f} /$ SuccessStories_MexicoHospitals.pdf?MOD=AJPERES

[22] American Hospital Assocation. Fast Facts on US Hospitals. Available from: www.aha.org/research. 2013. Retrieved January 1, 2014.

[23] Das, Anapreeta. Judge rules in case of fortune tied to Buffett. Wall Street Journal. September 1, 2013; B1.

[24] Queen of Angles Hospital v. Younger. 136 Cal. Rptr. 36 (Cal. 1977). 